\title{
Religion and entrepreneurial intentions: an empirical investigation
}

\author{
Qasim Riaz ${ }^{1, *}$, Muhammad Farrukh ${ }^{2}$, Shams-Ur- Rehman ${ }^{3}$, Amir Ishaque $^{3}$ \\ ${ }^{1}$ Mohi-UD-Din Islamic University, Azad Jammu and Kashmir, Pakistan \\ 2Institute of Graduate Studies, SEGi University, Petaling Jaya, Malaysia \\ ${ }^{3}$ National University of Modern Languages, Islamabad, Pakistan
}

\section{ARTICLE INFO}

\section{Article history:}

Received 25 May 2016

Received in revised form

13 August 2016

Accepted 17 September 2016

\section{Keywords:}

Entrepreneurship

Entrepreneurial intention

Students

Religion

\begin{abstract}
A B S T R A C T
This current study aimed to investigate the impact of religion on entrepreneurial intentions of the final year business students in private higher educational institutes of Pakistan. Data were collected with the help of a structured questionnaire; a total number of 290 responses were collected from the students studying in private higher educational institute. Structural Equation Modelling (SEM) was employed and data were analysed using SmartPLS version 2 software. The empirical results of the study reveal that, religion has a highly significant impact on Entrepreneurial Intention (beta $=0.316 \mathrm{t}=5.1125$ ). Government should consult the Islamic scholars and religious leaders to consolidate an entrepreneurial model; this could help in promoting the entrepreneurship which will ultimately help in poverty alleviation.

(C) 2016 The Authors. Published by IASE. This is an open access article under the CC BY-NC-ND license (http://creativecommons.org/licenses/by-nc-nd/4.0/).
\end{abstract}

\section{Introduction}

Every religion gives some instructions and guide lines to its followers to lead the life. These include all fields of its follower's lives like moral, social and even economic aspects. Religion does not only teach and guides in spiritual matters but it also illuminates the way to economic growth and outputs for its people.

Entrepreneurial motivation has been researched tremendously and it suggests that entrepreneurial behaviour responds to a variety of social factors as well as to the religion. That's why entrepreneurs are clearly woven by and highly affected by their socio cultural environment. Current study is primarily focused on economic behaviour of individuals and particularly entrepreneurial intentions are of major concerns in this study. To cut it short the study is aimed to test whether or not religiosity has an effect on entrepreneurial intentions. Preliminary work has been done to answer this question. All those studies used and implemented different scales or variables.

In the field of social sciences, the study of religion and specially the economic aspect is rather a new phenomenon. But there are some who claim that Weber's the Protestant ethics and the Spirit of

\footnotetext{
* Corresponding Author.

Email Addresses: qasimriaz1986@yahoo.com (Q. Riaz),

mfarrukhiqbal@hotmail.com (M. Farrukh) https://doi.org/10.21833/ijaas.2016.09.006

2313-626X/C) 2016 The Authors. Published by IASE.

This is an open access article under the CC BY-NC-ND license

(http://creativecommons.org/licenses/by-nc-nd/4.0/)
}

Capitalism, in 1905 was the first to identify economic role of faith. As argued by Lannaccone (1998) Adam smith was the first who started modern study of economics of religion. Investigation of Anderson (1988) is about the aspects of wealth of nation in which the economics of religion is highlighted. Whatever the case may be it is a fact that importance of religion as an informal institution in various aspects of human life has been attracting the attention of economists. Due to this increase in research in examining the economic function of the religion a new trend has arisen in quantitative studies.

Each society has its own code of Value System according to which the individual of that society live and this is an agreed upon behaviour of that society and held at high esteem. Therefore, business value formation is also influenced by socio-cultural and personal back ground factors. Among these factors are age, ethnicity, religion as well as education of the individual (Alwis and Senathiraja, 2003; Isa and Shitu, 2015). So in a society moulding of an entrepreneur is found to be deeply rooted in the socio-cultural environmental factors of that society. Every religion has a specific role of its value system in determining whether or not an individual can become an entrepreneur. As well as social institutions may also affect the way an individual perceives the role of being an entrepreneur and the extent to which an individual desires to be an entrepreneur. 
Now days, entrepreneurship is recognised overwhelmingly as a primary engine of economic growth and development. Therefore entrepreneurs' role is becoming very important to the dynamics of a society. For they are the one who combine existing resources with innovative ideas to create new economic goods and services resulting in creating new jobs. To cut short, entrepreneurs are now a link between the new ideas and economic growth and development. With regard to the current study the question is, whether the religious practices of the people affect their entrepreneurial intentions? Is there any link between the level of religiosity and entrepreneurial activities?

In the following section we will describe the concept of entrepreneurial intentions and its relationship with religiosity, followed by the Islamic perspective on entrepreneurship and theoretical arguments on the relationship between religion and entrepreneurial intentions.

\section{Entrepreneurial intention}

Intention has propensity to predict the individual behavior and action is the outcome behavior. (Krueger, 1993). Thus, intention linked to the entrepreneurial activities has been proven to be the predictor of entrepreneurial behavior (Reynolds, 1995). Autio et al. (2001) proposed that intentions can explain about $30 \%$ variance in behavior. Therefore, studying the entrepreneurial intention has attracted the interest of many researchers which results many model and theories linked to the explanation of what governs the individuals to engage in entrepreneurship.

The knowledge of Entrepreneurial intentions provide an insight to scholars, relating to what triggers opportunity scanning, sources of ideas for business venture and how the new venture idea could actually be transformed into reality (Krueger et al., 2000). Moreover, how the exploitation of discovered opportunities could be carried out successfully with minimum risks (Fini et al., 2009). The study of entrepreneurial intentions is a mean through which entrepreneurship research is advanced and facilitates to understand entrepreneurial activities being different from strategic management (Isa and Shitu, 2015).

\section{Religion and entrepreneurial Intentions}

The studies in the field of, economics of religion gives consensus that religion affects economic performance but the impact happens through different channels which are essence of religious teaching and principles.

Anderson (1988) with reference to Adam's theory of moral sentiments points out that religious beliefs provide strong incentives to follow moral restrains such as trust, honesty, benevolence and restraints from violence that have affects on civil society. Iannaccone (1995) points out that all religions work to instil certain values, morals and behavioural frameworks in their followers and those values, morals and beliefs are recognised in almost all aspects of human behaviour. Anderson (1988) points out another similar argument that belief or fear of god leads adherents to abide by "a kind of internal moral enforcement mechanism".

Entrepreneurship has no specific religion or culture for it cuts across all religions and also exists in diverse socio-cultural contexts, each of which represents a symbol of global entrepreneurial behaviour (Valliere, 2008). No doubt religion affects certain personal values like honesty, perseverance, bravery foresightedness and general standards positively (Altimay and Wang, 2011). Religion is one of the factors that determine the basic values and beliefs of people (Bwisa and Ndolo, 2011). Therefore, religion is vital in determining the extent to which the individuals take entrepreneurship as a career or not (Garba et al., 2013; Isa and Shitu, 2015). Audretsch et al. (2007) showed that religion influences entrepreneurial participation in their empirical paper. Mainstream Indian religions were compared in their study. It was found that there is a difference between religions according to entrepreneurial participation rate and the decision to become an entrepreneur. A big difference was found among various religions after investigating over 87000 people in India. More participation in entrepreneurship is shown by Christians and Jainism as compared to Buddhist and Hindus. The underlying reasons are suggested but not explained. As, not all the religions are mentioned in the study, therefore a difference between India and other countries can be expected according to these findings. As mentioned earlier the economic status may affect the role of entrepreneurship since there is a difference in per capita income (Van Stel et al., 2005).

One can look into the association between religion and level of entrepreneurial activity from different angles. Religious factors and entrepreneurship, both are aggregated in this paper for the individual level analysis. Therefore the theoretical reasoning behind the empirical study is based on individual behaviour analysis.

As discussed in previous sections, religions provide moral and ethical foundations for their adherents encouraging them to behave in a specific way. So the economic behaviour might be directly affected by the impact on traits and attitudes and indirectly by influencing factors which themselves influence economic outcomes. Through institutional sources, religion may also influence economic results. Public commitment to a religious organization, attending religious services signal the acceptance of religious code of conduct. This creates incentives among possible transaction partners to use religion as a signal for specific characteristics of a person and teaching of religion as second under the influence of the socio-religious network of which they are a part themselves.

Adherence to religion and its practices, according to Nikolova and Simroth (2013), often expose followers to new behavioural pattern which alters all 
their life style in its ramifications. Furthermore as stated by Barro and McCleary (2003) economic growth is highly influenced by the religion from the angles of beliefs, practices, governmental influences etc. Religious influence on societal and political events often tends to be long term continually affecting general entrepreneurial activities (Williamson et al., 2007).

Similar association between entrepreneurship and religion was also found by Dodd and Gotsis (2007). This association is to be very context specific as it lines with the already reported findings of Sternberg and Wennekers (2005). They stated that economic situation may influence the role of entrepreneurship. That's the reason that relation between entrepreneurship and religion is different over time subject to the economic situation and social settings influenced by other socio-cultural variables like political structures, ideologies and religious symbolism at work. (Dodd and Gotsis, 2007) concluded that individual elements influence the decision to become an entrepreneur. According to their findings if religious salience is high, entrepreneur would tend to use more religious arguments in their decisions for entrepreneurship, even when the decision has the negative influence on their commercial interest.

\section{Theoretical argument}

The study of religion in the realm of social sciences, particularly economics, is relatively a new phenomenon. However some claim Weber"s the Protestant Ethic and the Spirit of Capitalism, in 1905, was the first to identify economic role of faith. Although the theory draws its clues mainly from Protestant religion, but it concurs in general agreement that religiosity breeds entrepreneurial mindset and ultimately the risk takers. In this theory religion is the driving force of entrepreneurship. Theory further explains that entrepreneurs become the role performers in line with the expectations of the society; such expectations are purely the product of their religious beliefs, taboos and customs. Religion is pointed out by the theory as a major catalyst of entrepreneurship and emphasizes on the spirit of capitalism which entails economic freedom and enterprise in societies (Weber, 1930).

Bwisa and Ndolo (2011) stated that Weber acclaimed that religion encourages all traits that translate into entrepreneurial activities. Moreover religious values build the need for achievement in individuals based on the premise that a person's life is measured by his end result. This means that whatever a person does in life finally calculates as part of his positive or negative scores depending on the outcomes of the decisions taken (Weber, 1930).

Religion is one of the main components of the society and it is proven historically that most religions have positive influence towards entrepreneurship. This is evident in most of the globally accepted religions through their doctrines and ethics of spirituality, where adherents are motivated towards working hard to earn a means of survival (Deutschamann, 2001; Lunn and Klay, 2003).

Religion is the bedrock of success in entrepreneurship as believed and described by the Protestant Ethics and spirit of Capitalism. Motivation injected by the religion into the individual often results in success in entrepreneurship. Religion convincingly drives individual into entrepreneurial activities. Because religion preaches hard work and steadfastness in doing right; desire to earn more, the power of wealth acquisition (Isa and Shitu, 2015). Most religious traditions, in one or the other way address the interplay between entrepreneurship and religion (Weber, 1930). Need for achievement appears to have a strong connection with religion and could eventually breed entrepreneurial intentions (Isa and Shitu, 2015; Saffu, 2003).

In conclusion, theory high lights the fact that religion ignites some characteristics in individuals that propels them to desire to achieve more and as such become inquisitive, goal driven and achievement oriented. In this way they become much better individuals compared to what they were before in their sphere of life and these attributes are the clear distinction between an entrepreneurial mind person and non-entrepreneurial minded person (Garvey, 2003; Isa and Shitu, 2015; Lunn and Klay, 2003).

\section{Methodology}

This study is a replication of (Isa and Shitu, 2015), they conducted their research in African culture which is quite different from the Asian especially Pakistani culture in a number of aspects, therefore, it is imperative to re-conduct the study in a different setting to validate the results for generalization of findings.

\section{Instrument}

A structured questionnaire was developed by adopting item from already validated measures, For measuring religiosity we utilized (Mokhlis, 2008) and for measuring entrepreneurial intentions we utilized Leong (2008). Five likert scale point was used to measure the responses. The sample of this study was the students of business education in the private sector universities located in Lahore, Pakistan. A total number of 500 questionnaires were distributed among the final year students of the management sciences department of the targeted universities.

\section{Analysis}

The current study utilized Structural Equation modelling. The research utilized the partial least square (PLS-SEM) tool for the assessments of measurement and structural model. SmartPLS2.0 software (Hair et al., 2014) was used to execute the PLS-SEM analyses.

Evaluation of the model by SmartPLS involves two steps, in the first step internal consistency 
reliability, convergent validity model is assessed. According to Höck and Ringle (2006), the accepted value for composite reliability is the greater value of 0.6. From Table 1, we can see that minimum value of 0.6 is achieved which means internal consistency is established. To determine the convergent validity, average variance extracted (AVE) was applied in this study to show the average communality for each latent variable. The accepted value of AVE is greater than 0.5 in an adequate model (Höck and Ringle, 2006). The results in Table 1 show that AVE is also established. From the Table 1, we can see that all the threshold values were achieved.

Table 1: Quality criteria of measurement model

\begin{tabular}{|c|c|c|c|c|c|}
\hline \multirow{2}{*}{$\begin{array}{c}\text { 1st order } \\
\text { Religiosity }\end{array}$} & Items & Loadings & AVE & CR & Cronbach $\alpha$ \\
& Rel1 & 0.7204 & 0.60 & 0.89 & 0.87 \\
\hline & Rel 2 & 0.7797 & & & \\
\cline { 2 - 7 } & Rel 3 & 0.7775 & & & \\
& Rel 4 & 0.8471 & & & \\
\cline { 2 - 7 } Entrepreneurial Intentions & Rel 5 & 0.7117 & & & \\
\hline & EI1 & 0.704 & 0.65 & 0.80 & 0.82 \\
\hline & EI 2 & 0.7967 & & & \\
\hline & EI 3 & 0.6255 & & & \\
\hline & EI 5 & 0.7984 & & & \\
\hline
\end{tabular}

\section{R squared}

The $\mathrm{R}$ squared value depicts the predictive capability of the model. $R^{2}$ value for the endogenous constructs (EI) is found as 0.35

\section{Hypothesis testing}

The relationship of structural model is determined by the path coefficient among the construct of the study (Hair et al., 2014). Critical values for two tailed and one tailed are 1.96 and 1.65 respectively. By the use of bootstrapping function of SmartPLS 2 we calculated the t statistics with 5000 re-sampling as suggested by Hair et al. (2014). Table 2 shows the $\mathrm{T}$ statistics of the respective hypothesis and the decision taken on the basis of $t$ statistics.

Table 2: Hypothesis testing

\begin{tabular}{|c|c|c|c|c|}
\hline \multicolumn{2}{|c|}{ Hypothesis } & Beta & SE & \multicolumn{1}{c|}{ T } \\
statistics & Decision \\
\hline Rel -> EI & 0.3161 & 0.0495 & 5.1125 & supported \\
\hline
\end{tabular}

\section{Discussion and conclusion}

Religion is a key factor shaping personality of individuals. Religion is the one factor that often determines the social action of individuals. Also, religion defines many of the everyday habits of believers. Therefore religion affects the economic activity of individuals too. A key finding of this research is the direct connection of religion with entrepreneurial intentions.

Simply, it means that more religious an individual is, more likelihood that individual may embrace the entrepreneurship. Because once religion is embraced and its virtues are upheld, it overhauls the mindset of the individual. Therefore this result is a true reflection of what is practically obtainable in the society under study. The results of this study has endorsed the findings of previous researchers such as (Garba et al., 2013; Isa and Shitu, 2015)

Islam is the main religion of people of Pakistan and the main teachings of Islam as postulates by Solaiman and Hillaly (1997) such as faithfulness, perseverance, hard work, focus, foresight etc. are the attributes of entrepreneurs. There are similarities between the teachings of Islam and entrepreneurship. The former guides towards striving to survive through hard work, perseverance, foresight and independence (self-employment) in order to earn a living ( create wealth) rather than lean on others (salary, jobs), the later labels the aforementioned qualities as what make up an entrepreneur (Azim, 2008; Isa and Shitu, 2015). As a matter of fact, doing business or entrepreneurship is part of Islamic culture (Vargas Hernandez et al., 2010).

Students are future leader and entrepreneurs who should be taken as an asset of the society, therefore, they must be provided with opportunities as well as encouragement from all walks of life particularly from religious angle to take entrepreneurship as career. Ultimately, this could result in an entrepreneurial economy, which is the dire need of many economies, such as Pakistan. Government should consult the Islamic scholars and religious leaders to consolidate an entrepreneurial model; this could help in promoting the entrepreneurship which will ultimately help in poverty alleviation.

\section{Recommendations for future research}

This study focused on direct association between religiosity and entrepreneurial intentions and ignored the effects of culture; therefore it is strongly recommended that future researches should incorporate cultural as another factor.

\section{References}

Altinay L and Wang CL (2011). The influence of an entrepreneur's socio-cultural characteristics on the entrepreneurial orientation of small firms. Journal of Small Business and Enterprise Development, 18(4), 673-694.

Alwis WD and Senathiraja R (2003). The impact of socio-cultural background of the entrepreneur on 
management and business practices of selected small and medium scale businesses in Sri Lanka. In9th International Conference on Sri Lanka Studies, 28th-30th November.

Anderson GM (1988). Mr. Smith and the Preachers: the Economics of Religion in the Wealth of Nations. Journal of Political Economy, 96(5):1066-1088.

Audretsch DB, Boente W, and Tamvada JP (2007). Religion and Entrepreneurship. Jena Economic Research Paper No. 2007-075. Available at SSRN: https://ssrn.com/abstract=1025968 http://dx.doi.org/10.2139/ssrn.1025968.

Autio E, Keeley RH, Klofsten M, Parker GGC, and Hay M (2001), Entrepreneurial Intent among Students in Scandinavia and in the USA. Enterprise and Innovation Management Studies, 2(2): 145-160.

Azim MT (2008). Socio-cultural environment for entrepreneurship development in Bangladesh. Journal of Bangladesh Studies, 10(1): 51-60.

Barro RJ and McCleary R (2003). Religion and Economic Growth across Countries. American Sociological Review, 68(5): 760-781.

Bwisa HM and Ndolo JM (2011). Culture as a factor in entrepreneurship development: A case study of the Kamba culture of Kenya. International Journal of Business Management, 1(1): 20-29.

Deutschmann C (2001). Capitalism as a religion? An unorthodox analysis of entrepreneurship. European Journal of Social Theory, 4(4): 387-403.

Dodd SD and Gotsis G (2007). The interrelationships between entrepreneurship and religion. The International Journal of Entrepreneurship and Innovation, 8(2): 93-104.

Fini R, Grimaldi R, Marzocchi GL and Sobrero M (2009). The foundation of entrepreneurial intention. Conference proceedings in Summer Conference, Frederiksberg, Denmark.

Garba AS, Mansor SA and Djafar F (2013). An Exploratory Study on the Constraints for Entrepreneurial Activity: A Case of Micro and Small Enterprises in Kano, Nigeria. Journal of Applied Management and Entrepreneurship, 18(4): 79-93.

Garvey, G. E. (2003). The theory of the firm, managerial responsibility, and catholic social teaching. Journal of Markets and Morality, 6(2): 525-540.

Hair Jr J, Sarstedt M, Hopkins L and Kuppelwieser V (2014). Partial least squares structural equation modeling (PLS-SEM) An emerging tool in business research. European Business Review, 26(2): 106-121.

Höck M and Ringle CM (2006). Strategic networks in the software industry: An empirical analysis of the value continuum. International Journal of Knowledge Management Studies, 4(2): 132-151.

Isa A and Shitu S (2015). Impact of religion on entrepreneurial intention of university students in Kano state, Nigeria. In Proceedings of ICIC2015-International Conference on Empowering Civilization in the 21st Century: 6-7.

Krueger N (1993). The impact of prior entrepreneurial exposure on perceptions of new venture feasibility and desirability. Entrepreneurship: Theory and Practice, 18(1): 522.

Krueger NF, Reilly MD and Carsrud AL (2000). Competing models of entrepreneurial intentions. Journal of Business Venturing, 15(5): 411-432.

Lannaccone LR (1998). Introduction to the Economics of Religion. Journal of Economic Literature, 36(1): 1465-1495.

Leong CK (2008). Entrepreneurial intention: an empirical study among Open University Malaysia (OUM) students. Ph.D dissertation, Open University Malaysia (OUM)).

Lunn J and Klay R (2003). The Relationship of God's Providence to Market Economics and Economic Theory. Journal of Markets and Morality, 6(2): 541-564.

Mokhlis S (2008). Consumer religiosity and the importance of store attributes. The Journal of Human Resource and Adult Learning, 4(2): 122133.

Nikolova E and Simroth D (2013). Does Cultural Diversity Help or Hinder Entrepreneurs? Evidence from Eastern Europe and Central Asia, European Bank for Reconstruction and Development, London.

Reynolds PD (1995). Who Starts New Firms? Linear Additive Versus Interaction Based Models. The Babson-Kauffman Entrepreneurship Research Conference, London.

Saffu K (2003). The role and impact of culture on South Pacific island entrepreneurs. International Journal of Entrepreneurial Behavior and Research, 9(2): 55-73.

Solaiman M and Hillaly SR (1997). Problems and prospects of entrepreneurship development of Muslim Ummahs: the case of Bangladesh. Cost and Management, 25(6): 36-45.

Sternberg R and Wennekers S (2005). Determinants and effects of new business creation using global entrepreneurship monitor data. Small Business Economics, 24(3): 193-203.

Valliere D (2008). Exploring Buddhist influence on the entrepreneurial decision. International Journal of Entrepreneurial Behavior and Research, 14(3): 172-191. 
Van Stel A, Carree M, and Thurik R (2005). The effect of entrepreneurial activity on national economic growth. Small Business Economics, 24(3): 311321.

Vargas-Hernández JG, Noruzi MR, and Sariolghalam $N$ (2010). An exploration of the affects of Islamic culture on entrepreneurial behaviors in Muslim countries. Asian Social Science, 6(5): 120-127.
Weber M (1930). The Protestant Ethic and the Spirit of Capitalism. $1^{\text {st }}$ Edition, Scribner, New York, USA.

Williamson SA, Deusen CA Van and Perryman AA (2007). The Influence of National Religious Consciousness on Entrepreneurial Behavior. International Business Research Teaching and Practices, 1(1): 53-75. 